\title{
Development and Evaluation of a Thin Cerium Oxide-Gelatin Nanolaminate Coating for Corrosion Protection of AISI 316L Stainless Steel
}

\author{
Mohammed T. Hayajneh (ORCID: 0000-0001-8328-207), Mohammed Almomani (ORCID: \\ 0000-0003-1034-9022), Mohammad Al-Daraghmeh (ORCID: 0000-0001-9224-3795) \\ Industrial Engineering Department, Faculty of Engineering, Jordan University of Science and Technology, \\ P.O. Box 3030, Irbid, 22110, Jordan, E-mail: hayajneh@just.edu.jo, maalmomani7@just.edu.jo, \\ myd-araghmeh9@just.edu.jo.
}

\begin{abstract}
AISI 316L stainless steel is widely used for multiple applications because of its good mechanical properties and corrosion resistance in multiple environments. However, the long exposure of AISI 316L steel to aggressive envi-ronments containing chloride ions limits its electrochemical performance significantly. The objective of this re-search is to develop and evaluate a thin cerium oxide-gelatin nanolaminate coatings for corrosion protection of the spin-coated AISI 316L stainless steel in $3.5 \% \mathrm{NaCl}$ solution as the corrosion medium. The nanolaminate coat-ings were evaluated by the potentiodynamic polarization technique and the characterization of the coatings was performed by using XRD, SEM, and EDX. The results show that the corrosion behaviour of $\mathrm{CeO}_{2}$-gelatin nano-laminate coatings significantly improves the corrosion behaviour of the coated AISI 316L steel. The results also confirm the formation of homogeneous and crack-free coatings without any noticeable defect. One-way ANOVA analysis was used to examine the statistical significance of coating types. The novelty of this research is the devel-opment and preparing nanocomposites coatings by using gelatin as a gel matrix for nanocomposites powder dispersion instead of the traditional methods to improves the uniform and localized corrosion of the AISI 316L steel. The results showed that the prepared coatings significantly improved the uniform and localized corrosion re-sistance of the AISI 316L steel.
\end{abstract}

Keywords: Corrosion evaluation, Nanolaminate coating, Cerium oxide, Gelatin, AISI 316L stainless steel, Spin coating

\section{Introduction}

AISI 316L stainless steel is widely used for multiple applications because of its good mechanical properties and very good corrosion resistance in multiple environments [1]. Its uses cover a wide range of applications such as medical applications, household, nuclear power plants, marine environments, architecture, and transportation applications [2]. AISI 316L steel loses its superior corrosion resistance behaviour and suffers from localized corrosion with the presence of chloride ions in seawater and body fluids [3]. Therefore, surface modification techniques are necessary to protect the outer surface of AISI 316L steel from direct contact with severe corrosion environments. Several surface engineering procedures have been considered in the literature to improve the corrosion resistance of AISI 316L steel without deteriorating its properties. These procedures can be applied either by grain refinement [4], adding alloying elements to the AISI 316L steel surface, or by coating the surface of the steel by single or multiple protecting layers [5].

Cerium (Ce) is the most plentiful of rare earth elements that are found in the earth's crust [6]. Recently, cerium oxide has been extensively used in biological applications due to its antioxidant behaviour in cell culture systems [7]. Also, it is used in corrosion protection applications as a single or hybrid coating material for various surfaces. Arora et al. [8] synthesized novel lanthanum cerium molybdate (LCM) nanoparticles by sol-gel synthesis method and their use in the development of nanocontainers in an anticorrosive coating application. The self-healing and anticorrosion effects of cerium nitrate in epoxy-clay nanocomposite coatings systems were studied [9]. Different amounts of cerium (III) were added to epoxy-montmorillonite clay composites and the nanocomposite coatings were prepared and applied on cold rolled steel panels

There are few studies in the literature covering AISI-316 coated with cerium oxide film. Shi et al. [10] investigated the corrosion resistance of AISI-316 coated with cerium oxide film by magnetron sputtering technique and concluded that ceria film improves the corrosion resistance of AISI-316 substrate significantly in a simulated marine environment. $\mathrm{Xu}$ et al. [11] developed a new cerium chemical conversion coating composed of $\mathrm{CeO}_{2}$ with a small amount of $\mathrm{Ce}_{2} \mathrm{O}_{3}$ on AISI-316 substrate and analyzed the corrosion behaviour of such coating in a simulated marine environment and concluded that such coating improves the 
critical pitting potential of AISI-316 substrates in a simulated hot marine environment.

Gelatin is a natural biological macromolecule derived from the collagen in the connective tissue of the skin, bone and other tissues. It has been widely used in medicine, food and industrial production and other fields for easy molding, excellent compatibility and biodegradability [12]. Gelatin has many advantages such as good adhesiveness and moderately low cost, which makes it a good choice for medical applications [13], pharmaceutical applications [14], and protective coating material [15]. Gelatin is becoming a promising candidate as a composite coating material in engineering applications. Almomani et al. [16] and Hayajneh et al. [17] used gelatin as a gel matrix for nanoparticles dispersion instead of the old and traditional sol-gel method.

This study evaluates the corrosion behaviour of nanolaminate $\mathrm{CeO}_{2}$-gelatin coating applied to AISI 316L Stainless Steel in a simulated marine environment containing $3.5 \% \mathrm{NaCl}$ solution. The influence of the weight percentage of $\mathrm{CeO}_{2}$ nano powders on corrosion behaviour and morphology of the produced coatings is also tested.

\section{Materials and Methods}

\subsection{Preparation of AISI 316L steel substrates}

AISI 316L steel substrates were cut into $55 \mathrm{~mm} \times$ $55 \mathrm{~mm} \times 2 \mathrm{~mm}$. Before coating, the AISI 316L substrates were dipped in a solution comprising of nitric acid and hydrogen peroxide for 30 seconds to increase the binding of gelatin coating to the AISI 316L substrates by increasing the micro-roughness of the AISI 316L substrates. Then the substrates were cleaned in Acetone for 15 minutes by an ultrasonic cleaner to remove any contaminants on the surface of the substrates. Finally, the substrates were sonicated in deionized water for 15 minutes and dried by a hot air stream before the coating stage.

\subsection{Preparation of nanolaminate $\mathrm{CeO}_{2}$-gelatin-coa- tings}

To prepare the coating materials, different quantities of cerium dioxides nanoparticles $(10-30 \mathrm{~nm}$, purity $>99.97 \%$, density $7.132 \mathrm{~g} / \mathrm{cm} 3$, US Research Nanomaterials company) were dispersed in gelatin at different weight percentages. Gelatin (type A porcine skin, Mw: 50,000-100,000, Sigma) was selected as a standard 8 wt. $\%$ gelatin in 20 wt. $\%$ acetic acids [16, 17]. The solution was prepared at room temperature. After complete gelatin dissolution, different weight percentages of $\mathrm{CeO}_{2}$ nanoparticles $(0,1,2,3)$ wt. $\%$ were added to the solution. Magnet stirrer was used at room temperature for 24 hours to assure homogeneous distribution of $\mathrm{CeO}_{2}$ nanoparticles in the suspension. To stabilize the gelatin structure in water, crosslinking is necessary. Ethyl-3-(3-dimethylaminopropyl) carbodiimide (EDC, Sigma) was used as a crosslinking agent. 9 wt. \% EDC solutions in ethanol were added to the suspension and magnetically mixed for 6 hours at 50o C [16].

Spin-coating films were developed using a KW-4A precision spin-coater (Chemat Technology Inc.) with the help of a vacuum pump (Gast Manufacturing). In this investigation, the spinning speed setting was adjusted according to the initial experiments on the three spinning speed sets (L: 250-1000 rpm, M: 500-2500 rpm, H: 750-4000 rpm) based on the electrochemical results and visual evaluation of the coating smoothness quality. Accordingly, the 500-2500 rpm spinning speed setting was chosen. Spinning time was attuned for all coated samples to be 15 seconds for the low spinning speed and 30 seconds for the high spinning speed.

\subsection{Characterization of the nanolaminate coatings}

The morphology of the coated steel was inspected by scanning electron microscopy (SEM), and energydispersive $\mathrm{X}$-ray analysis (EDX) before the corrosion experiment to explore the homogeneity and distribution of the nano powders within the gelatin matrix, and after the corrosion experiment to identify the influence of corrosion test on the morphology of the coated steel. Energy-dispersive X-ray analysis was used for elemental analysis and chemical characterization of the substrate surface and corrosion products. The phase identification of the coated samples was executed using X-ray diffraction (XRD) to confirm the presence of $\mathrm{CeO}_{2}$ nanoparticles within the coating on the AISI 316L steel. Direct current polarization (DCP) experiment was used to study the corrosion behaviour of the coated AISI 316L steel. Gamry potentiostat Ref 600 corrosion testing apparatus was used with graphite and saturated calomel electrodes as a counter and reference respectively. Three replicate samples were tested for each case to ensure repeatability.

\subsection{Statistical analysis}

The use of statistical models has allowed the explanation of the behaviour of many natural phenomena. However, their application in the investigation of the corrosion behaviour has been extensively used in recent studies [18]. Analysis of variance (ANOVA) is a statistical analysis tool, it stands for analysis of variance, and developed by the British researcher Ronald Fisher in 1923 to analyze the differences between group means to determine whether they are the same or not by splitting the causes of variability in a data into two parts: systematic and random factors. ANOVA has been used in many applications including materials science. Materials scientists and researchers utilize ANOVA to investigate the influence of 
changing some controlled process parameters or weight percentages of reinforcement or alloying elements on various material properties based on the experimental results [19-20]. In the present study, ANOVA is used to check whether the changes in the exchange current density and thus corrosion rate or pitting potential at different weight percentages of $\mathrm{CeO}_{2}$ are statistically significant at $95 \%$ confidence level or they occurred from normal variations.

It is important to emphasize that if the ANOVA test shows that the variations of electrochemical parameters (Icorr and Epit) at different weight percentages of $\mathrm{CeO}_{2}(0,1,2$ and 3$)$ are significant, and then this is a sign for the change of corrosion mechanism.

\section{Results and Discussion}

3.1 Chemical characterization of $\mathrm{CeO}_{2}$-gelatin coatings

Figure 1a shows the uncoated AISI 316L surface before performing the corrosion test. It can be observed that the surface has irregular-shaped mark lines that were formed during the polishing process by detaching some material from the surface parallel to the polishing lines. Figure $1 \mathrm{~b}$ shows SEM images of the pure gelatin-coated sample before the corrosion test. It can be seen that the surface is totally covered by a very smooth, homogeneous, and well-distributed gelatin layer and without any cracks or defects. Figure 1c shows SEM images of 2 wt. $\% \mathrm{CeO}_{2}$ nanolaminate coated sample before carrying out the corrosion test. The figure confirms the uniform and homogeneous distribution of $\mathrm{CeO}_{2}$ nanoparticles throughout the gelatin matrix without affecting the morphology or the adhesion of the gelatin matrix coating to the AISI 316L steel substrate. Figures 1d represents the EDX spectrum and quantitative analysis of the coated AISI 316L steel with $\mathrm{CeO}_{2}$ nanoparticles distributed in gelatin matrix before the corrosion test. The figure proves the presence of $\mathrm{CeO}_{2}$ nanoparticles in the gelatin matrix.
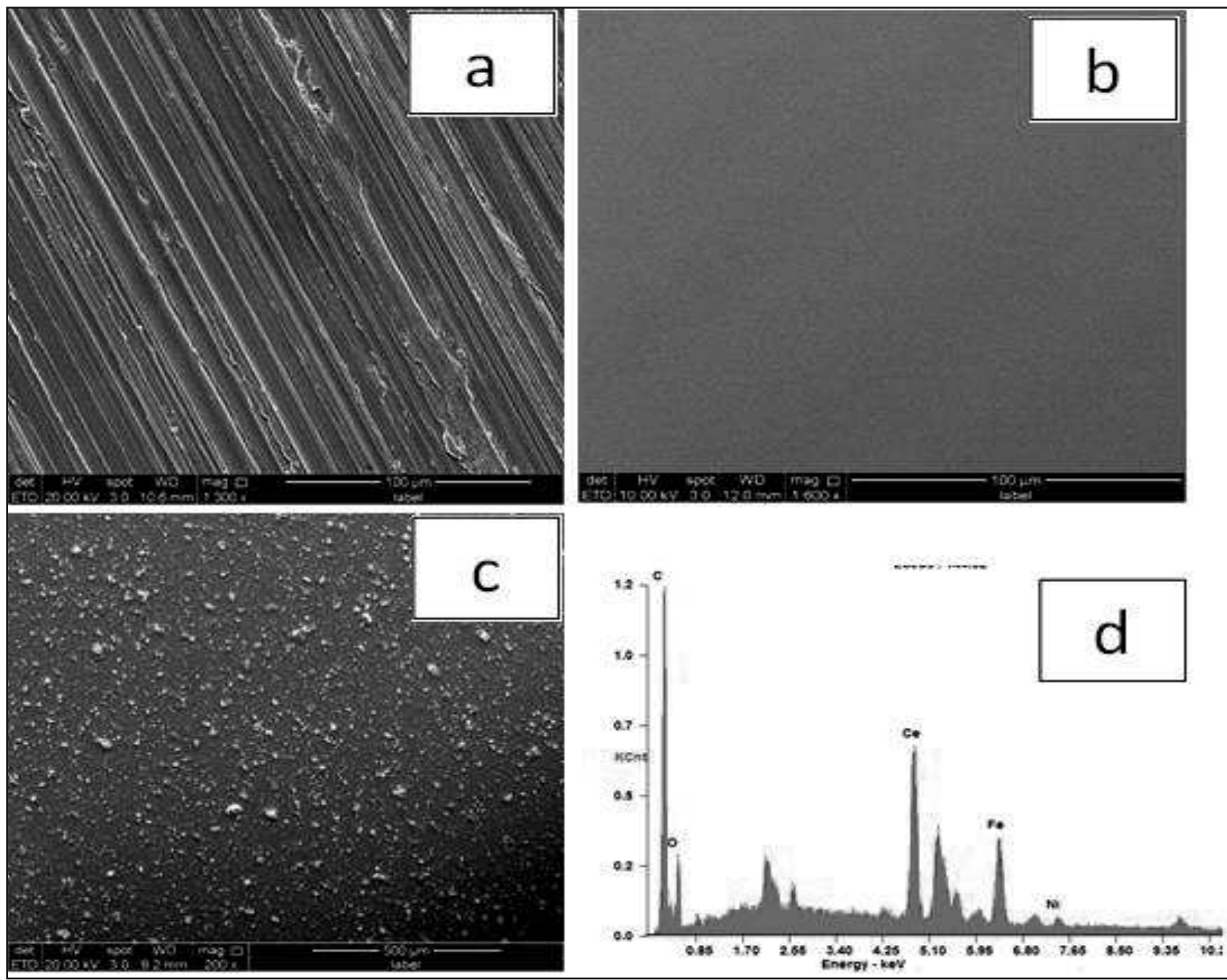

Fig. 1 (a) Surface morphology of AISI 316L stainless steel before conducting the corrosion test, (b) SEM images of a pure gelatincoated sample before the corrosion test, (c) SEM images of $2 \mathrm{wt} . \% \mathrm{CeO}_{2}$-gelatin nanolaminate coating before corrosion test, (d) EDX spectrum and quantitative analysis of coated AISI 316L steel with $\mathrm{CeO}_{2}$ nanoparticles dispersed in gelatin before corrosion 
Figure 2 displays the uncoated AISI 316L steel surface morphology after corrosion testing. The Figure shows that the entire surface is covered with brittle cracked layers of salts filled with the corrosion products. The cracks formation can be attributed to internal stresses spurred by the released gases during the cathodic reactions, or it can be formed as a result of the salt layer. It also can be seen from Figure 2 that the uncoated AISI $316 \mathrm{~L}$ steel surfaces are covered with many pits or cavities of different sizes that affect adversely the surface morphology and quality. The gelatin coating layer without $\mathrm{CeO}_{2}$ nanoparticles completely deteriorated and unsuccessful to protect the AISI 316L steel surface from corrosion as shown in Figure 3. Such behaviour can be attributed to the lack of hard dielectric ceramic nanoparticles in the gelatin coating. As shown in Figure 4, the distribution of $\mathrm{CeO}_{2}$ nanoparticles in gelatin improves the performance of the gelatin coating in protecting AISI 316L steel after performing the corrosion test leaving it without any cracks and pits. The SEM images after the corrosion experiment confirmed the presence of the nano-sized $\mathrm{CeO}_{2}$ particles in the gelatin coating and some microsized agglomerations in addition to the precipitation of aggressive salt layers, which is a decent measure of the stability and the functionality of this coating. Figure 5 shows the EDX spectrum and the quantitative analysis of the coated AISI $316 \mathrm{~L}$ steel with $\mathrm{CeO}_{2}$ nanoparticles dispersed in gelatin after the corrosion test. Both (EDX spectrum and quantitative analysis) prove the presence of $\mathrm{CeO}_{2}$ nanoparticles in gelatin coating after performing the corrosion experiment in addition to the presence of precipitated aggressive chloride ions in the surface of the substrate.
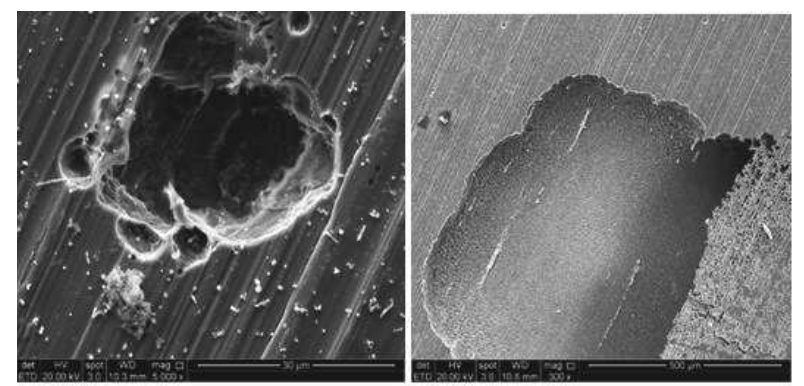

Fig. 2 Surface morphology of uncoated AISI 316L stainless steel after conducting the corrosion test.
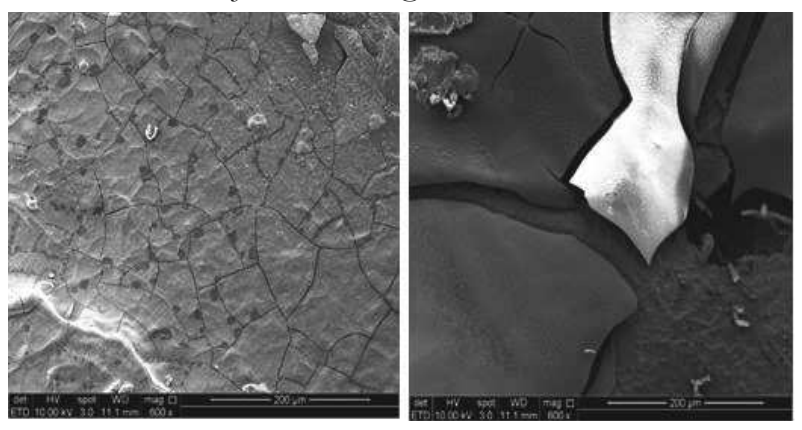

Fig. 3 SEM images of pure gelatin-coating after the corrosion test.

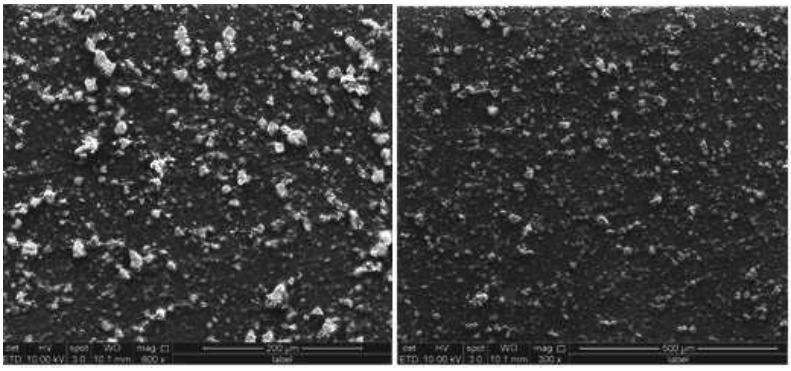

Fig. 4 SEM images of nanolaminate $2 \mathrm{wt} . \% \mathrm{CeO}_{2}$-gelatincoating after the corrosion test.

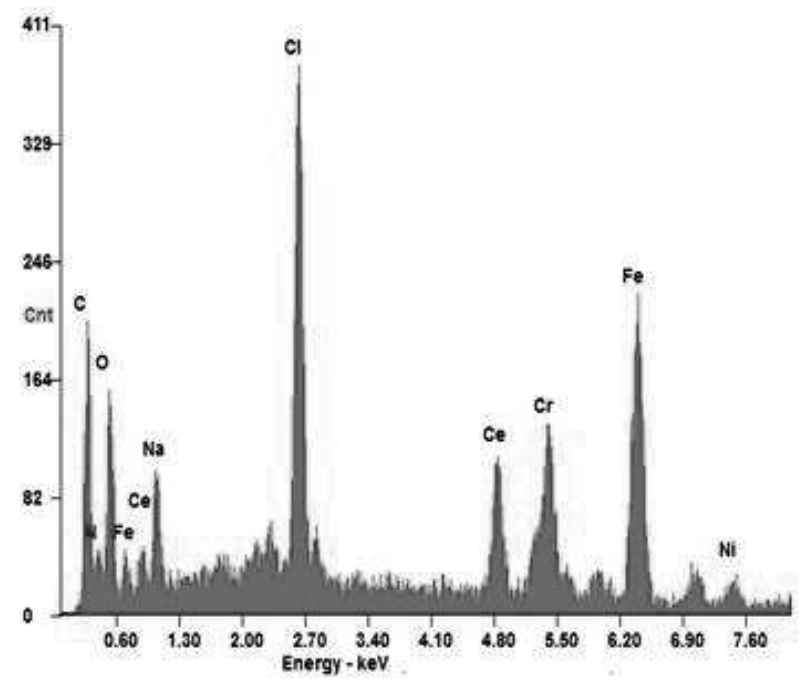

Fig. 5 EDX spectrum and quantitative analysis of nanolaminate $2 \mathrm{wt} . \% \mathrm{CeO}_{2}$-gelatin-coating after the corrosion test

\section{$3.2 \mathrm{XRD}$ analysis}

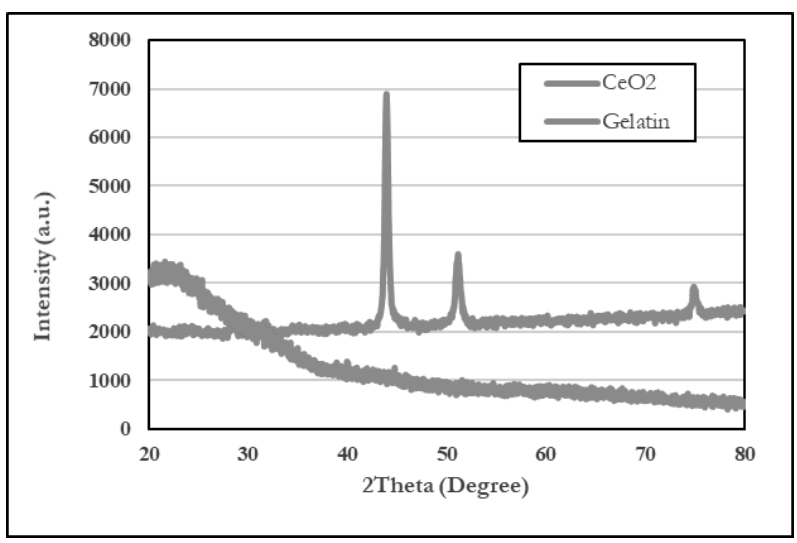

Fig. 6 XRD pattern of pure gelatin and $\mathrm{Ce}_{2}$-gelatin-nanolaminate on a fused glass substrate

$\mathrm{X}$-ray diffraction (XRD) was used to confirm the presence of $\mathrm{CeO}_{2}$ nanoparticles within the nanolaminate gelatin- $\mathrm{CeO}_{2}$ coating. Figure 6 shows the XRD patterns of the gelatin and the $\mathrm{CeO}_{2}$-gelatin- nanolaminate on a fused glass substrate. The figure shows the X-ray diffraction patterns of pure gelatin, revealing that the structure is essentially amorphous with a more pronounced peak [21] at around $20^{\circ} 2 \theta$, having intensities of $\sim 3400$. Figure 6 also shows the XRD pattern of 2 wt. $\% \mathrm{CeO} 2$ nano powders dispersed in gelatin 
nanolaminate consisted of the main characteristic peaks of $\mathrm{CeO}_{2}$ at $2 \theta$ of the diffraction peaks observed at $20: 28.66^{\circ}, 33.03^{\circ}, 44.56^{\circ}, 56.39^{\circ}, 69.34^{\circ}$, and $76.61^{\circ}$. These patterns reveal the presence of crystalline cerium dioxide $\left(\mathrm{CeO}_{2}\right)$ deposits (Joint Committee of Powder Diffraction Standards-JCPDS \#431002).

\subsection{Electrochemical corrosion examination}

Figure 6 The polarization curves of 316L steel coated with cerium oxide-gelatin nanolaminate coatings are shown in the plot of Figure 7. The curves for all the examined nanolaminate coatings have similar shapes and are made of the same regions, which are: cathodic branch, anodic branch, and autocatalytic pitting region. On each curve, the corrosion current decreases with raising the applied potential in the first region which starts from the lowest potential on the curve and extends up to the point where the corrosion current starts to increase with the increase of applied potential. The first region is known as the cathodic branch of the curve. The point at which the current starts to increase with increasing the potential represents the start of the second region, this region continues to the point where a sharp increase of the current resulting from a small increase of the applied potential.
In this region, pits might form but they disappear, transient current spikes are signs for these metastable pits formation. The end of the second region is known as critical pitting potential which represents the potential level at which the metastable pits become stable and continue to grow in the last region (autocatalytic pitting). Almomani and Aita [5] describe in detail the morphology of pits growth in the autocatalytic region. Even though the similar characteristics curve for these nanolaminate coatings, but these curves differ in the position of exchange current density (Icorr), and the level of the critical potential. Figure 7 shows that the corrosion current densities (Icorr) are shifted to lower values with an increase of weight percentage $\mathrm{CeO}_{2}$ nanoparticles in the matrix, and at the same time, the critical pitting potentials are shifted to higher values. These changes indicate that both uniform and localized corrosion of AISI $316 \mathrm{~L}$ steel has improved by applying the used nanolaminate coatings. Therefore, adding the $\mathrm{CeO}_{2}$ nanoparticles to the gelatin matrix enhances the coating stability by slowing down the transport of corrosive agents through the nanolaminate coating. The cathodic inhibition imparted by the cerium oxide coating layer is much more significant than the uncoated AISI 316L steel substrates.

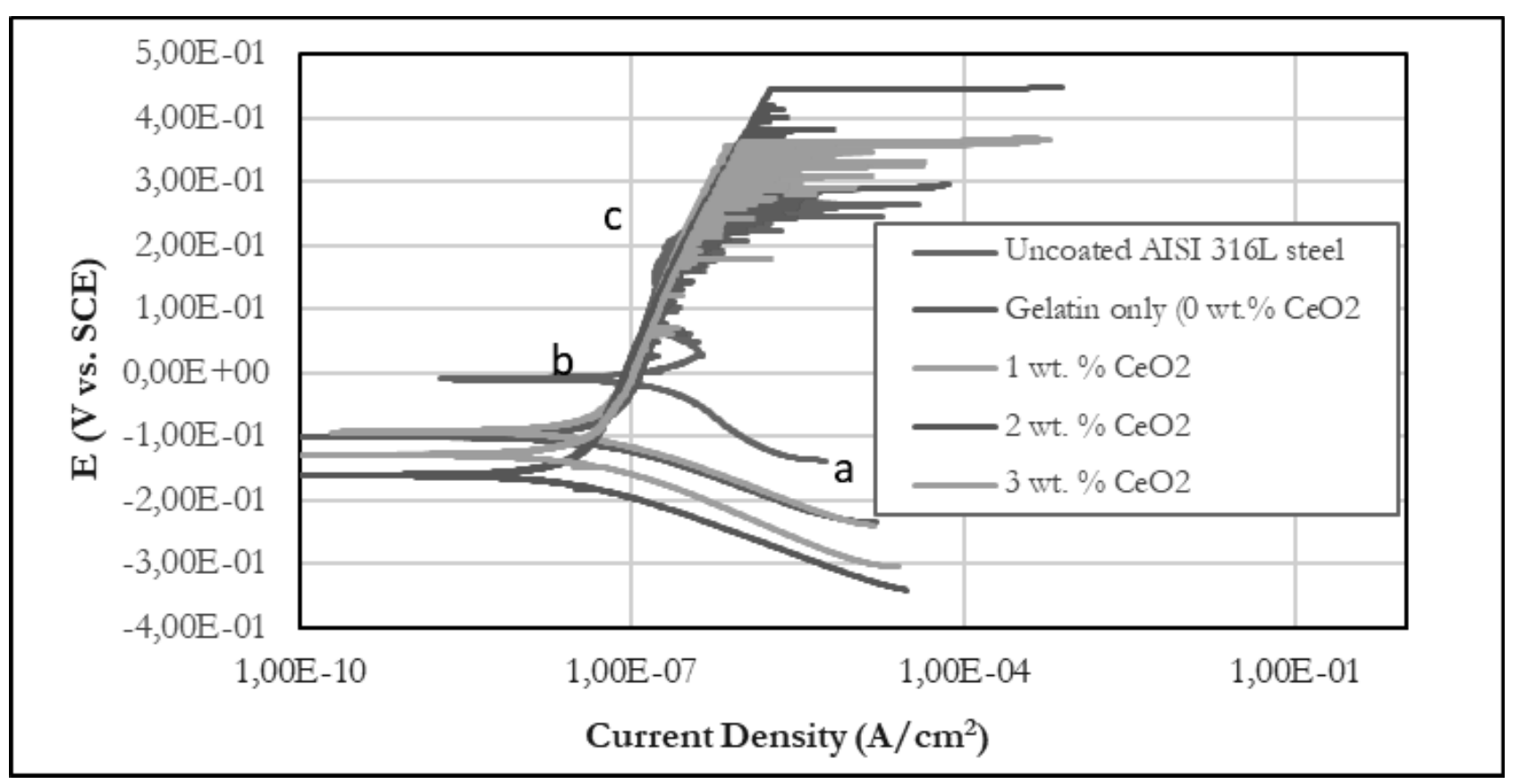

Fig. 7 Potentiodynamic polarization curves of AISI 316L steel coated with different nanolaminate $\mathrm{Ce}_{2}$-gelatin coatings.

Table 1 summarizes the corrosion potentials (Ecorr), corrosion current densities (Icorr), and critical pitting potentials (Epit) that were obtained from the Tafel scans for all examined samples. It can be observed from Table 1 that Icorr value indicates significant information about the corrosion behaviour; the sample that has the least corrosion current density experiences the best corrosion resistance.
Figure 8 shows the effects of the weight percentage of dispersed $\mathrm{CeO}_{2}$ nanoparticles on the corrosion current density of AISI 316L steel. As shown, the electrochemical results at $2 \mathrm{wt} . \% \mathrm{CeO}_{2}$ nanoparticles weight percentage outperform the electrochemical results at 3 wt. $\% \mathrm{CeO}_{2}$ weight parentage. These findings may be attributed to the agglomeration of $\mathrm{CeO}_{2}$ par- 
ticles which increases the surface roughness and speeds the corrosion [22]. The results indicate that the coating the steel surface with gelatin inhibits passivation. Shifts in Ecorr and Icorr resemble to the effectiveness of the coatings to limit the amount of solution contacting the steel, whereas the $\mathrm{CeO}_{2}$ particles provide localities susceptible to breaching at the thinner layers of the gelatin coat to permit the solution to contact the steel with no time to passivate. Figure 9 shows the critical pitting potential behaviour of AISI 316L steel coated with different weight percentages of $\mathrm{CeO}_{2}$ nano powders $(0,1,2,3)$. As shown, the $\mathrm{CeO}_{2}$ nanoparticles improve the critical pitting potential of the
AISI 316L steel significantly. This behaviour is due to the formation of stable coating layers on the AISI 316L steel surface compared with the unstable oxide film on the uncoated AISI 316L steel, which could not sufficiently protect against pitting corrosion [25]. It seems obvious that the critical-pitting potential results are compatible with the corrosion current density results; the highest electrochemical enhancement occurs at 2 wt. $\% \mathrm{CeO}_{2}$ nanoparticles coating due to the negative effect of agglomeration on the surface roughness and critical pitting potential.

Tab. 1 Electrochemical constant values for the uncoated and coated AISI 316L steel samples.

\begin{tabular}{|c|c|c|c|c|}
\hline The Examined Samples & $\begin{array}{l}\text { Percentage of the } \\
\mathrm{CeO}_{2} \text { nanoparticles } \\
(\text { wt. \%) }\end{array}$ & $\begin{array}{l}E_{\text {corr }} \\
(\mathrm{mV} \text { vs. SCE) }\end{array}$ & $\begin{array}{l}\mathrm{I}_{\text {corr }} \\
\left(\mathrm{nA} / \mathrm{cm}^{2}\right)\end{array}$ & $\begin{array}{l}\mathrm{E}_{\text {pit }} \\
(\mathrm{V} \text { vs. SCE) } \\
(\mathrm{mV}) \\
\end{array}$ \\
\hline \multirow{3}{*}{ Uncoated AISI 316L steel } & - & 37 & 196 & 277 \\
\hline & - & -9.02 & 272 & 270 \\
\hline & - & -158 & 260 & 286 \\
\hline \multirow{3}{*}{ Coated with gelatin only } & 0 & -101 & 75 & 291 \\
\hline & 0 & -125 & 67 & 312 \\
\hline & 0 & -161 & 133 & 271 \\
\hline \multirow{3}{*}{$\begin{array}{l}\text { Nanolaminate } \quad \mathrm{CeO}_{2} \text {-gelatin } \\
\text { coatings }\end{array}$} & 1 & -139 & 57 & 367 \\
\hline & 1 & -92 & 57.9 & 360 \\
\hline & 1 & -121 & 62.4 & 374 \\
\hline \multirow{3}{*}{$\begin{array}{l}\text { Nanolaminate } \quad \mathrm{CeO}_{2} \text {-gelatin } \\
\text { coatings }\end{array}$} & 2 & -157 & 49.9 & 457 \\
\hline & 2 & -161 & 37.6 & 443 \\
\hline & 2 & -174 & 46 & 454 \\
\hline \multirow{3}{*}{$\begin{array}{l}\text { Nanolaminate } \quad \mathrm{CeO}_{2} \text {-gelatin } \\
\text { coatings }\end{array}$} & 3 & -142 & 56.1 & 367 \\
\hline & 3 & -129 & 48.9 & 365 \\
\hline & 3 & -110 & 44.2 & 320 \\
\hline
\end{tabular}

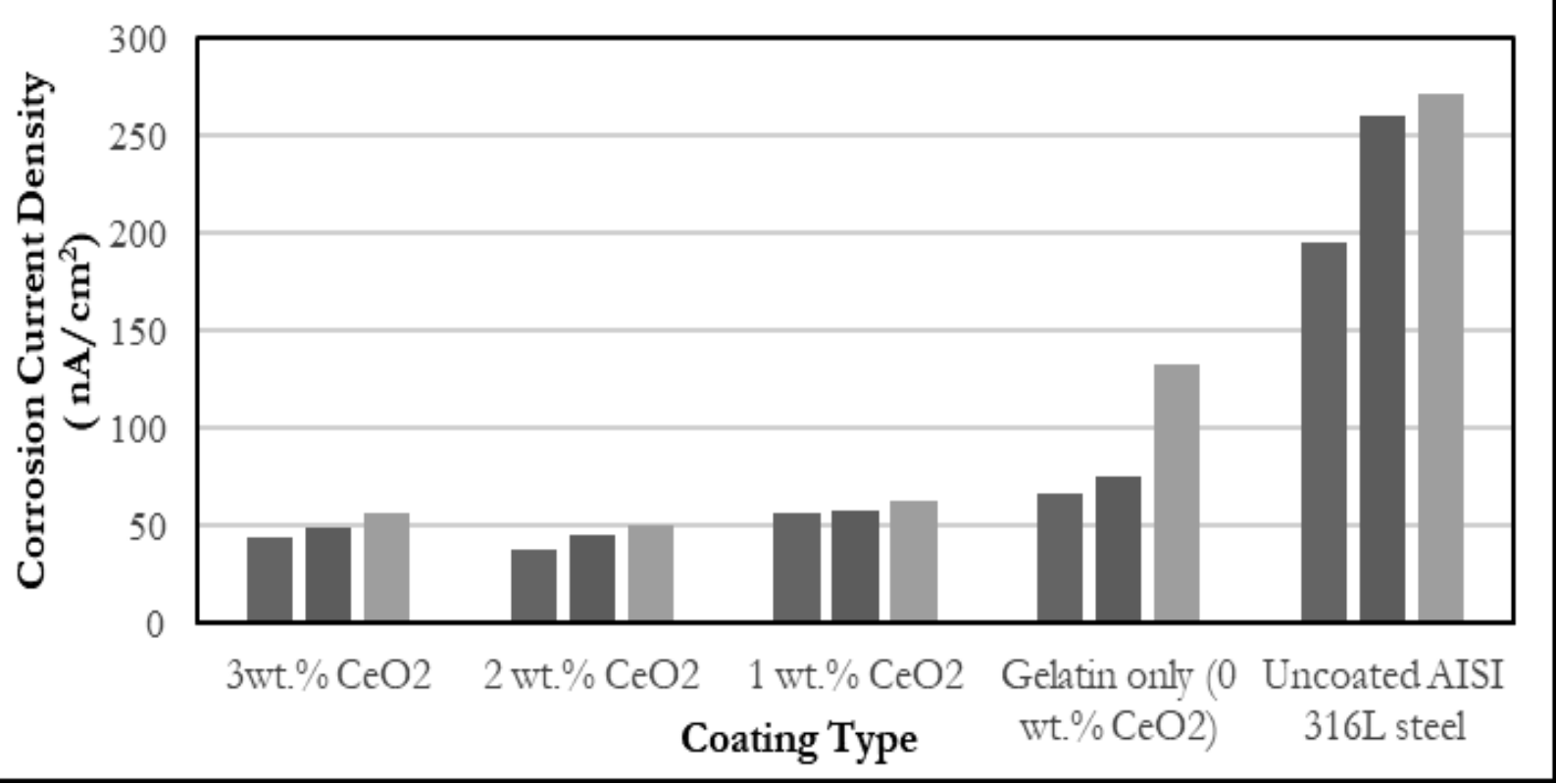

Fig. 8 Corrosion current density $\left(\mathrm{n} A / \mathrm{cm}^{2}\right)$ of AISI $316 \mathrm{~L}$ coated with different nanolaminate $\mathrm{Ce}_{2}$-gelatin coatings. 


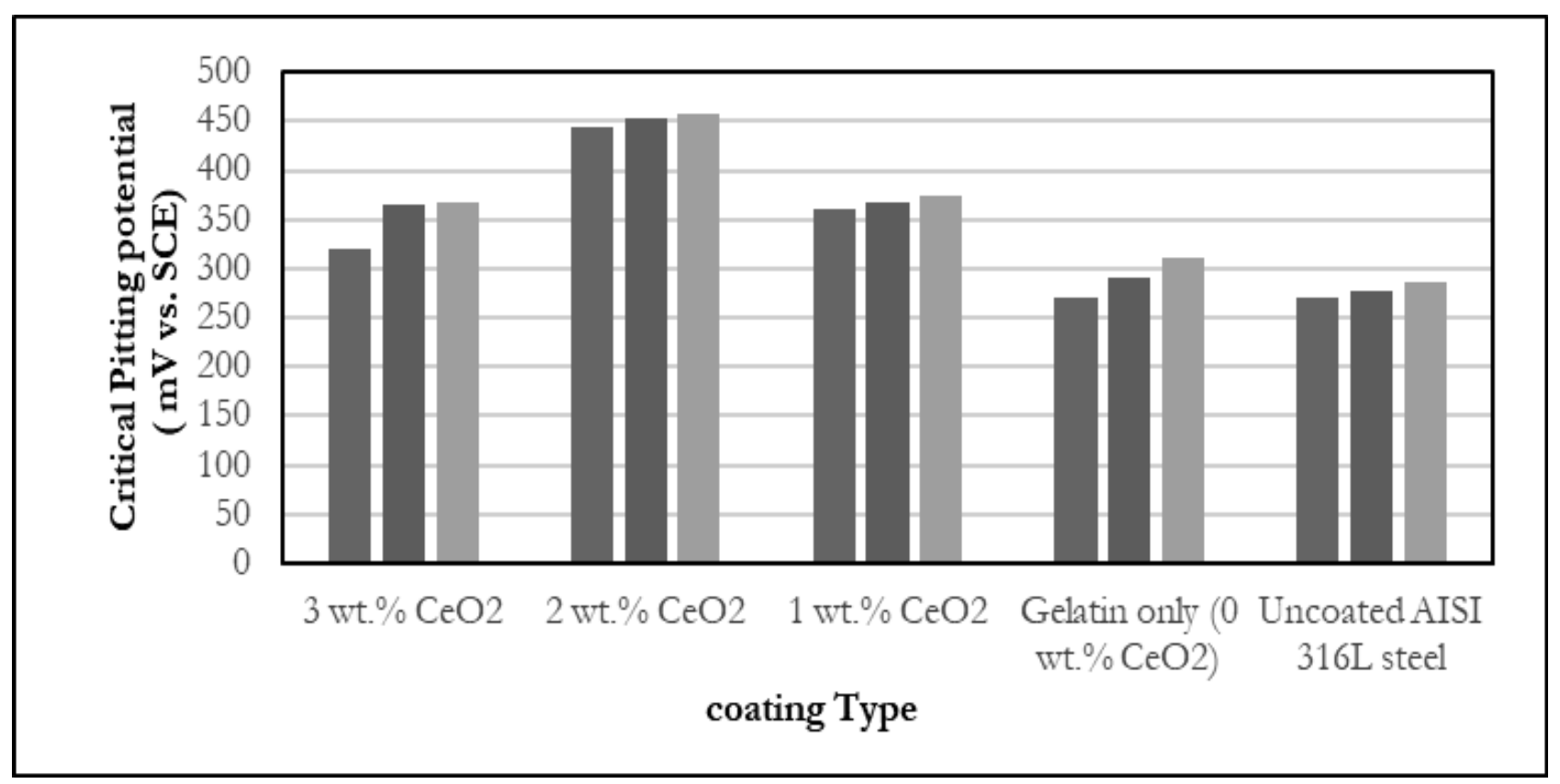

Fig. 9 Critical pitting potential ( $m V$ vs. SCE) of AISI 316 L coated with different nanolaminate $\mathrm{CeO}_{2}$-gelatin coatings.

\subsection{Statistical analysis}

A one-way ANOVA analysis was used to examine the statistical significance of the coating types on corrosion current density and critical pitting potential. This analysis was evaluated for a confidence level of $95 \%$, that is for the significance level of $\alpha=0.05$. Minitab software (version 18) was used to perform the test. Five coating type levels were tested: uncoated AISI 316L steel, AISI 316L steel coated with only gelatin (0 wt. $\left.\% \mathrm{CeO}_{2}\right)$, AISI 316L steel coated with 1 wt. $\% \mathrm{CeO}_{2}$-gelatin nanolaminate coating, and AISI 316L steel coated with 2 wt. \% $\mathrm{CeO}_{2}$-gelatin nanolaminate coating and AISI 316L steel coated with $3 \mathrm{wt}$. $\% \mathrm{CeO}_{2}$-gelatin nanolaminate coating. Each level has three replications. ANOVA test results of the effect of coating type on corrosion current density and critical pitting potential are briefed in Tables 2 and 3, respectively. Since the P-value for the models was less than 0.05 , then the parameter or interaction can be considered to be statistically significant.

Figures 10 and 11 show the boxplot of the corrosion current density (Icorr) of AISI 316L versus the coating type and the boxplot of the critical pitting potential (Epit) of AISI 316L versus the coating type, respectively. A boxplot is a graph that gives a good indication of how the values in the data are spread out. The results confirm that the corrosion current density and the critical pitting potential are dependent on the coating type. It is shown that all coating types can improve the critical pitting potential of the uncoated AISI 316L significantly, which is due to the formation of stable coating layers on the AISI 316L surface compared with the unstable oxide film on the uncoated AISI 316L steel. The best electrochemical enhancement occurs at 2 wt. $\% \mathrm{CeO}_{2}$ nanolaminate coating. The statistical analysis fully supports the electrochemical and morphology results.

Tab. 2 ANOV A test results of the corrosion current density $\left(I_{\text {corr }}\right)$ for each coating type

\begin{tabular}{|c|c|c|c|c|c|}
\hline Source & Df & SS & MS & F & P \\
\hline Coating types & 4 & 81195 & 20299 & 31.86 & 0.000 \\
\hline Error & 10 & 6371 & 637 & & \\
\hline Total & 14 & 87566 & & & \\
\hline
\end{tabular}

Tab. 3 ANOV A test results of the critical pitting potential $\left(E_{\text {pit }}\right)$ for each coating type

\begin{tabular}{|c|c|c|c|c|c|}
\hline Source & Df & SS & MS & F & P \\
\hline $\begin{array}{c}\text { The Examined } \\
\text { Sample }\end{array}$ & 4 & 60213 & 15053 & 60.10 & 0.000 \\
\hline Error & 10 & 2505 & 250 & & \\
\hline Total & 14 & 62718 & & & \\
\hline
\end{tabular}




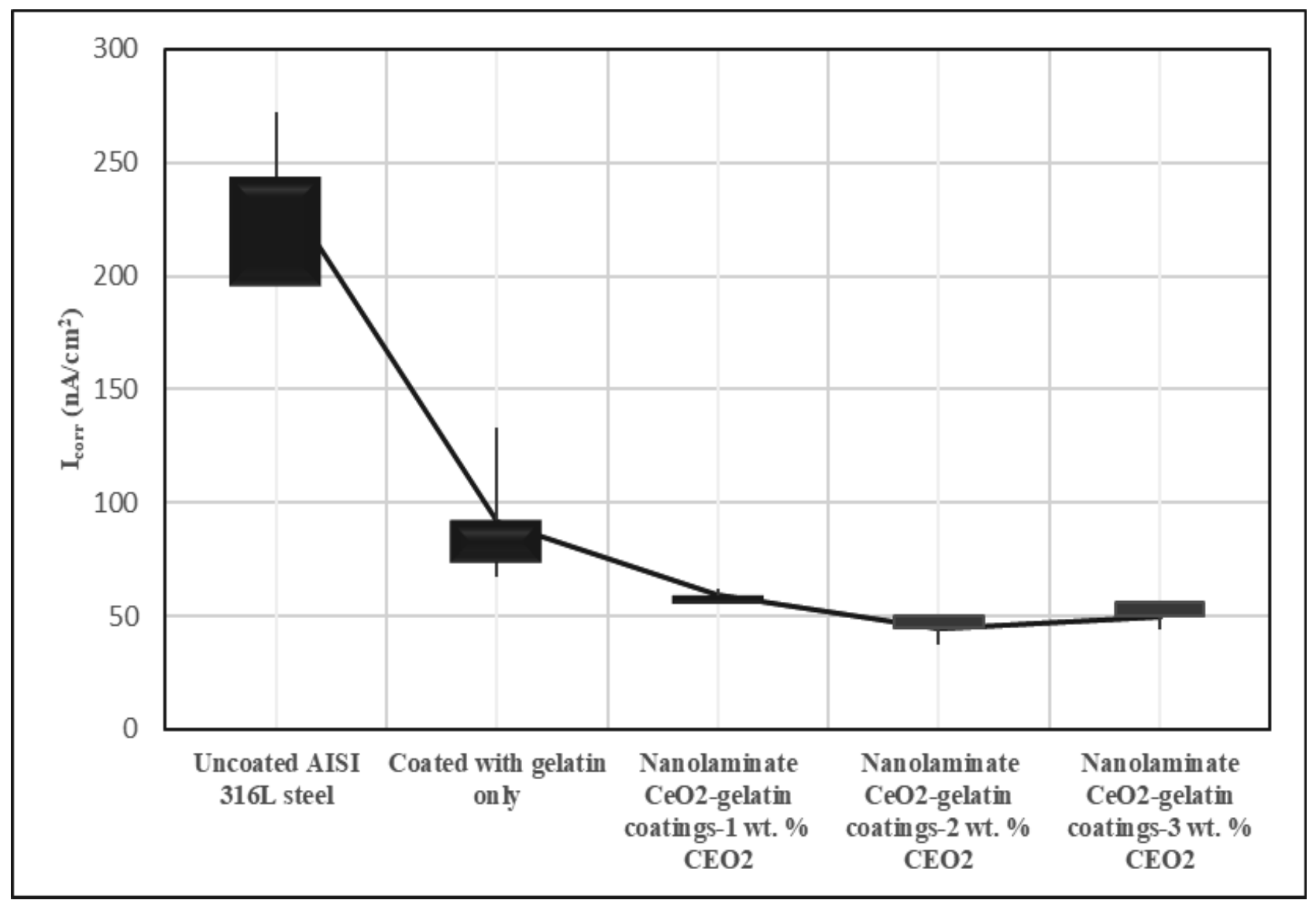

Fig. 10 Boxplot of corrosion current density (Icorr) of AISI 316L versus the coating type.

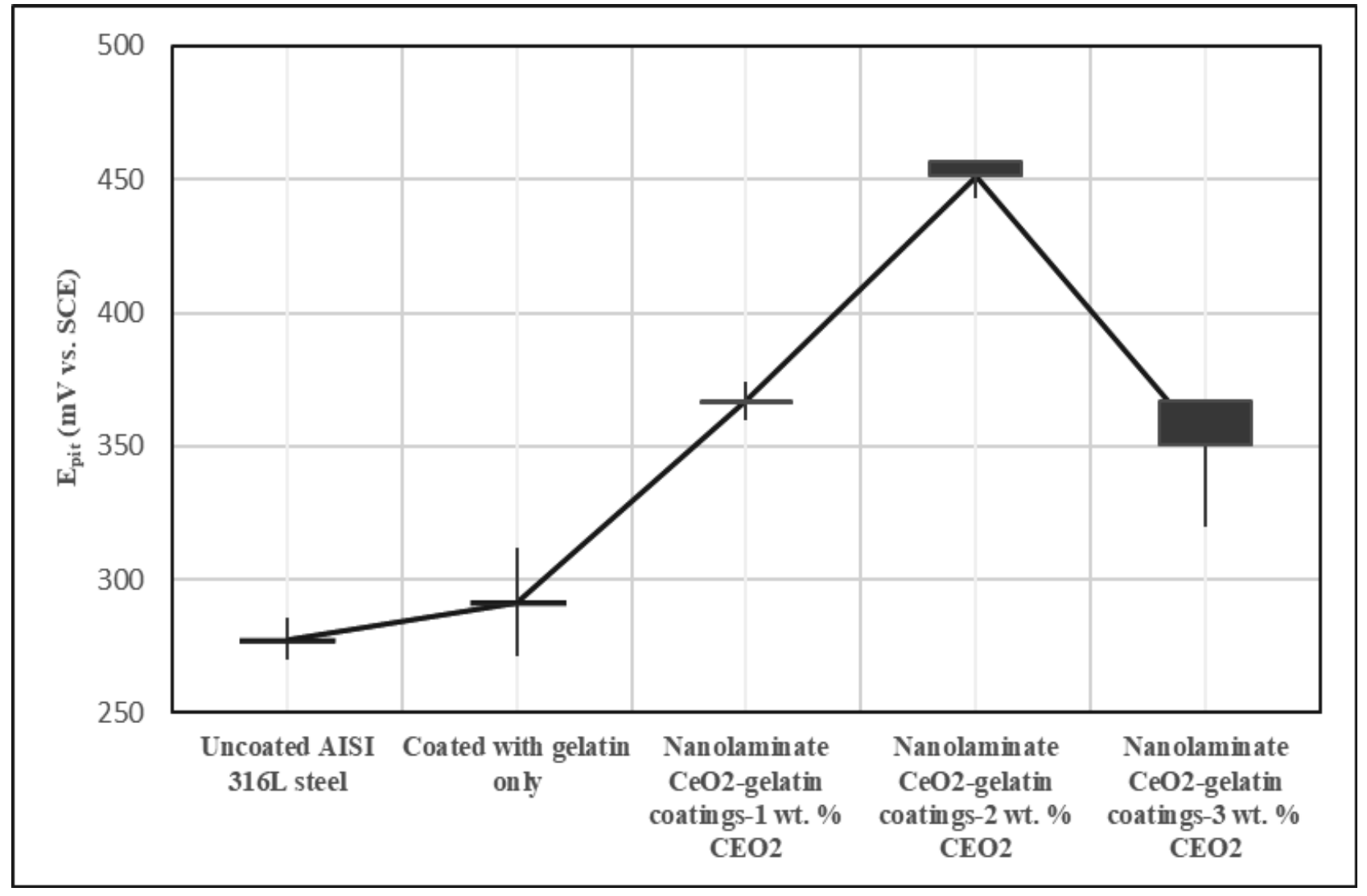

Fig. 11 Boxplot of critical pitting potential (Epit) of AISI 316L versus the coating type. 


\section{Conclusions}

Nanolaminate coatings with different weight percentages of $\mathrm{CeO}_{2}$ nanoparticles $(0,1,2,3)$ were well prepared on AISI 316L steel substrates using the spin coating technique at $250-2500 \mathrm{rpm}$ spinning speed setting. The results reveal the formation of a homogeneous and uniform coating without cracks. $\mathrm{CeO}_{2}$ nanoparticles dispersed in a gelatin matrix could significantly improve the AISI 316L electrochemical properties compared with the uncoated AISI 316L. Based on the findings of this study, the following can be concluded:

- $\mathrm{CeO}_{2}$-gelatin nanolaminate coatings can considerably improve both the corrosion resistance (diminish corrosion current density and pitting corrosion resistance as well as increase critical pitting potential) of AISI 316L steel.

- Nanolaminate coating with 2 wt. $\% \mathrm{CeO}_{2}$ exhibit higher pitting potential than nanolaminate coating with 3 wt. $\%$ of $\mathrm{CeO}_{2}$.

- $\mathrm{CeO}_{2}$-gelatin nanolaminate coatings improve the stability of the produced coating layers because it delays the transition of metastable pits to stable pits to a higher potential.

- The weight percentages of $\mathrm{CeO}_{2}$ in the nanolaminate coatings have a statistical significant influence on both corrosion current density and the critical pitting potential of AISI 316L steel substrate.

\section{Acknowledgements}

This work was supported by a grant from the Deanship of Scientific Research at Jordan University of Science and Technology (JUST) with grant no. 39/2017. The authors would also like to acknowledge the engineering workshop employee of JUST for their help in completing this work.

\section{References}

[1] ASHRAFI, A., GOLOZAR, M., MALLAKPOUR, S. (2009). Corrosion behaviour of 316L stainless steel coated by amorphous and semicrystalline polypyrrole. Surface Engineering, Vol. 25, No. 2, pp. 120-126.

[2] ZHAO, Y., ZHOU, F., YAO, J., DONG, S., LI, N. (2015). Erosion-Corrosion Behaviour and corrosion resistance of AISI 316 stainless steel in flow jet impingement. Wear, Vol. 328329, pp. 464-476.
[3] MAJEDI, A., DAVAR, F., ABBASI, A., ASHRAFI, A. (2016). Modified sol-gel based nanostructured zirconia thin film: preparation, characterization, photocatalyst and corrosion behavior. Journal of Inorganic and Or-ganometallic Polymers and Materials, Vol. 26, No. 5, pp. 932942.

[4] BOTTOLI, F., JELLESEN, M., CHRISTIANSEN, T., WINTHER, G., SOMERS, M. (2018). High temperature solution-nitriding and low-temperature nitriding of AISI 316: effect on pitting potential and crevice corrosion performance. Applied Surface Science, Vol. 431, pp. 24-31.

[5] ALMOMANI, M., AITA, C. (2009). Pitting Corrosion Protection of Stainless Steel by Sputter Deposited Haf-nia, Alumina, and HafniaAlumina Nanolaminate Films. Journal of V acuum Science \& Technology A, Vol. 27, No. 3, pp. 449.

[6] RICCARDO, BALZAROTTI, CINZIA CRISTIANI, SAVERIO LATORRATA, ALESSANDRO MIGLIAVACCA. (2015). Washcoating of low surface area cerium oxide on complex geometry substrates. Particulate Science and Technology, Vol. 34, No. 2, pp. 184193.

[7] DRÁPALA, J., MACHOVČÁK, P., JONŠTA, P., HA, VT., BROŽOVÁ, S., KOSTIUKOVÁ, G., MADAJ, M. (2015). Structural Characteristics of Cr-Mo Steels Microalloyed with Cerium. Manufacturing Technology, Vol. 15, No. 3, pp. 315322.

[8] ARORA, S., MESTRY, S., SINGH H, K., MHASKE, S. (2020). Sol-gel based layer-by-layer deposits of lantha-num cerium molybdate nanocontainers and their anticorrosive attributes. Iranian Polymer Journal, Vol. 29, pp. 133 146.

[9] DANAEE, I., DARMIANI, E., RASHED, G. R., ZAAREI, D. (2014). Self-healing and anticorrosive properties of $\mathrm{Ce}(\mathrm{III}) / \mathrm{Ce}(\mathrm{IV})$ in nanoclay-epoxy coatings. Iranian Polymer Joumal, Vol. 23, pp. 891-898.

[10] SHI, Z., ZHOU, Z., SHUM, P., LI, L. (2019). Thermal stability, wettability and corrosion resistance of sputtered ceria films on 316 stainless steel. Applied Surface Science, Vol. 477, pp. 166171.

[11] XU, J., XIN, S., HAN, P., MA, R., LI, M. (2013). Cerium chemical conversion coatings for corrosion protection of stainless steels in hot seawater environments. Material and Corrosion, Vo. 64, No. 7, pp. 619-624. 
[12] HAYAJNEH, MT., ALMOMANI, M., ALDARAGHMEH, M. (2019). Enhancement the Corrosion Resistance of AISI 304 Stainless Steel by Nanocomposite Gelatin-Titanium Dioxide Coatings. Manufacturing Technology, Vol. 19, No. 5, pp. 759-766.

[13] ZHONG, S., ZHANG, Y., LIM, C. (2010). Tissue scaffolds for skin wound healing and dermal reconstruction. Wiley Interdisciplinary Reviews Nanomedicine and Nanobiotechnology, Vo. 2, No. 5, pp. 210-525.

[14] DILLE, M., HATTREM, M., DRAGET, K. (2018). Soft, chewable gelatin-based pharmaceutical oral formula-tions: a technical approach. Pharmacentical Development and Technology, Vol. 23, No. 5, pp. 504-511.

[15] AL-DARAGHMEH, M., ALMOMANI, M., HAYAJNEH, M. (2019). Corrosion Resistance of $\mathrm{TiO} 2-\mathrm{ZrO} 2$ Nanocomposite Thin Films Spin Coated on AISI 304 Stainless Steel in 3.5 wt. $\% \mathrm{NaCl}$ Solution. Materials Research, Vol. 22, No. (5), pp. 1-9.

[16] ALMOMANI, M., HAYAJNEH, M., ALDARAGHMEH, M. (2019). The corrosion behavior of AISI 304 stain-less steel spin coated with $\mathrm{ZrO} 2$-gelatin nanocomposites. Mater Res Express, Vol. 6, No. 9, pp. 65c4.

[17] HAYAJNEH, M., ALMOMANI, M., AL_HMOUD, H. (2019). Corrosion evaluation of nanocomposite gelatin-forsterite coating applied on AISI 316L stainless steel. Mater Res Express, Vol. 6, No. 11, pp. 6431.

[18] SVOBODOVA, J., LUNAK, M., LATTNER, M. (2019). Analysis of the Increased Iron Content on the Corro-sion Resistance of the AlSi7Mg0.3 Alloy Casting. Manufacturing Technology. Vol. 19, No. 6, pp. 1041-1046.

[19] ESWARA KRISHNA, M., PATOWARI P, K. (2013). Parametric optimisation of electric discharge coating pro-cess with powder metallurgy tools using Taguchi analysis. Surface Engineering, Vol. 29, No. 9, pp. 183-189.

[20] ALMOMANI, M., HAYAJNEH, M., ALELAUMI, S. (2019). Applying Taguchi method to study the wear be-haviour of ZA-27 alloy-based composites reinforced with $\mathrm{SiC}$ nanoparticles. International Journal of Cast Metals Research, Vol. 32, No. 4, pp. 229-241.

[21] PAL, K., BANTHIA, AK., MAJUMDAR, DK. (2007). Preparation and characterization of polyvinyl alcohol-gelatin hydrogel membranes for biomedical applications. AAPS PharmSciTech, Vol. 8, No. 1, pp. E142-E146.

[22] TORKAMAN, R., DARVISHI, S., JOKAR, M., KHARAZIHETA, M., KARBASI, M. (2017). Electrochemical and in Vitro Bioactivity of Nanolaminate Gelatin-Forsterite Coatings on AISI 316 L Stainless Steel. Progress in Organic Coatings, Vol. 103, pp. 40-47. 